\title{
A risk assessment model of commercial real estate development projects in developing countries
}

\author{
Semra Comu*iD, Ayca Yetiskin Elibol ${ }^{\text {iD }}$, Busra Yucel iD \\ Bogazici University, Department of Civil Engineering, Istanbul, Turkey
}

\begin{abstract}
Commercial real estate investments play a direct role in economic welfare, yet they are high-risk investments, especially in developing countries. If the risk factors directly affecting the project objectives are not analyzed correctly, financial losses are inevitable in Commercial Real Estate Development (CRED) projects. In this respect, this study aims to identify and prioritize the risk factors and introduce an Analytic Network Process (ANP) model to assess the risks in CRED projects in developing countries. The findings of this study reveal the importance of "Exchange rate and inflation rate fluctuations," "Political instability," and "Location selection" risk factors for CRED projects in developing countries. Five case studies are also conducted to test and support the effectiveness of the proposed model. The proposed model provides a clear perspective for decision-makers or stakeholders of the CRED projects to assess their risk criteria in order to take proper actions.
\end{abstract}

\section{Keywords}

Risk assessment; Risk factors; Commercial real estate projects; Analytic network process

Received: 25 February 2021; Accepted: 29 March 2021

ISSN: 2630-5771 (online) (C 2021 Golden Light Publishing All rights reserved.

\section{Introduction}

Construction projects are of great importance in the economies of countries. They provide competitive advantages in producing economic value. In this regard, ILO [1] emphasizes the importance of adequate infrastructure as it is a prerequisite for sustainable economic growth and social development. Especially in developing countries, the construction sector has been a leading indicator in creating a more accessible environment and improving the quality of life. Distant places become accessible by roads and other means of transportation projects. Therefore, increasing infrastructure investments leads to open up new areas for the real estate industry, an important business segment of the construction sector. For this reason, several studies examine the real estate industry from various perspectives, including its relation to countries' economies, (e.g. [2, 3, 4, 48]). Significantly, the commercial real estate subsegment consisting of shopping malls, offices, hotels, and logistics, plays a direct role in the countries' economy and social life by increasing the living standards and offering new work opportunities. In 2018, only the commercial real estate sub-sector contributed $\$ 1.0$ trillion to U.S. GDP, generated $\$ 325.9$ billion in personal earnings, and supported a total of 8.3 million jobs [3]. The development and market potential of CRED projects, not only in developed countries but is also

\footnotetext{
* Corresponding author

Email: semra.comu@boun.edu.tr
} 
undeniably high for developing countries.

However, besides the significance of CRED projects in terms of contribution to economic growth, they are characterized by inherent risks and uncertainties resulting from their complex feature and competitive nature $[4,5]$. Reasons that cause the complexity and riskiness of real estate development projects include economy, government, and longterm trends, which are even more critical risk factors in developing countries [6]. Those risks and uncertainties affect the decision-making process and influence projects' objectives by leading to cost overrun, delay, and poor quality [7]. The type and magnitude of these risks may vary due to political and economic instability in developing countries. Therefore, more progress needs to be made for the risk assessment of CRED projects in developing countries. Instead of using general risk assessment methods available in the literature, with a risk assessment method specific to developing countries, adverse consequences can be avoided, and real estate projects' profits can be increased. In short, a decision-making system is required for the risk assessment of CRED projects specific to developing countries.

\section{Risk identification and categorization in real estate projects}

As construction projects have become more complex, they involve various risks and uncertainties that affect the cost, time, and quality of projects. For this reason, risk management is essential for the success of a project. In this regard, various risk assessment models have been developed to analyze and assess project risks (e.g., [8]). In the 1990s, the risk management concept gained significance in the construction industry. As one of the pioneer studies, Mustafa and Al-Bahar [9] developed a basic model for construction projects by categorizing the risk factors as; physical risks, financial and economic risks, political and environmental risks, design risks, and job-site related risks. Akintoye and MacLeod [10] surveyed project management practices to understand the construction industry's perception of risk. The study focused on environmental, political, social and economic, construction, market, and IT-related risk factors.

Similarly, Hastak and Shaked [11] constructed an international construction risk assessment model (ICRAM-1) that evaluates risk criteria including macro (country level), market, and project levels while expanding operations in the international market. The proposed model quantifies the risk involved in international construction investment and reveals four main results as follows: i) high-risk indicators, ii) the impact of the country environment on a specific project, iii) the impact of the market environment on a specific project, and iv) overall project risks. The hierarchies and analyses of risks identified at the macro level and construction market level are especially critical for developing countries' operations, where risk factors are more complicated. Kuo et al. [12] developed a Fuzzy Multiple Criteria Decision Making (FMCDM) approach for construction projects in metropolitan areas. Considering the complex environment of projects, the authors investigated risks by evaluating their likelihood and impact. The assessment involves five risk dimensions: engineering design, natural hazards, construction safety-related, social and economical, and construction management. Besides, to increase risk management effectiveness and complete construction projects without delays or cost overruns, El Karim et al. [13] analyzed and quantified construction risk factors. The study examines related risk elements under four main criteria, including site conditions, resources, project parties, and project features related factors and having several sub-criterions.

Therefore, while there are many risk assessment studies for the construction industry (e.g., [14-17]), a few studies (e.g., [4,18-20]) focus on real estate development and CRED projects in the literature. As a matter of fact, in CRED-related studies, risk identification and classification methods have been developed based on studies focusing on general construction projects. For example, Khumpaisal [21] emphasized the significance and possible impacts of risks faced in real estate development projects. The study approves that in this industry, 
risks generally stem from STEEP (Social, Technological, Economic, Environmental, and Political) factors and suggests grouping related risks under these five main categories. Chen and Khumpaisal [19] proposed a multicriteria decisionmaking approach to assess CRED risks. By underlining sustainable development, the paper describes SEET (Social, Economic, Environmental, and Technological) criteria and evaluates risks concerning the requirements of CRED projects.

On the other hand, Hwang et al. [22] investigated risk factors for green commercial building projects in Singapore. In this study, 29 critical risk factors are listed under seven categories: technical, labor, management, financial, legal, environmental, and political. The study also proposes risk mitigation measures for defined risk factors. Another research regarding CRED project risks was conducted by Thilini and Wickramaarachchi [20], which aims to define and evaluate risks in commercial property projects in Sri Lanka from the entrepreneur's perspective. Similar to Khumpaisal and Chen [7], this study presents CRED risks under environmental, social, economic, technological, and political risk. Consequently, real estate and CRED market-related studies are very limited in the literature.

Moreover, to the authors' best of knowledge, a study that examines the risk assessment method in CRED projects in developing countries does not exist. Governments have to deal with various problems in developing countries that threaten stability and constancy, such as the financial crisis and the forthcoming election [23]. However, these risk factors may not be applicable in developed countries, or they may not have as significant an impact in developed countries as in developing countries. Therefore, some changes in risk factors are inevitable for developing countries. In summary, most of the current studies in the literature examine the risk criteria from a very general perspective in various construction projects such as infrastructure or joint ventures $[4,11,15,24,25]$. Thereby, there is a gap in the literature on the risk factors encountered in CRED projects and their effects on the decision-making process in developing countries. To fill this gap, we aim to provide a model structure defining and evaluating the risks specific to CRED projects in developing countries.

\section{Research methodology}

This study aims to present a new decision-making tool to assess CRED-related risks in developing countries. Therefore, relevant risk factors were listed and clustered through an extensive literature review. After selecting critical risk factors, an ANPbased risk assessment model was developed and tested. Fig. 1 presents the main framework of the study in detail.

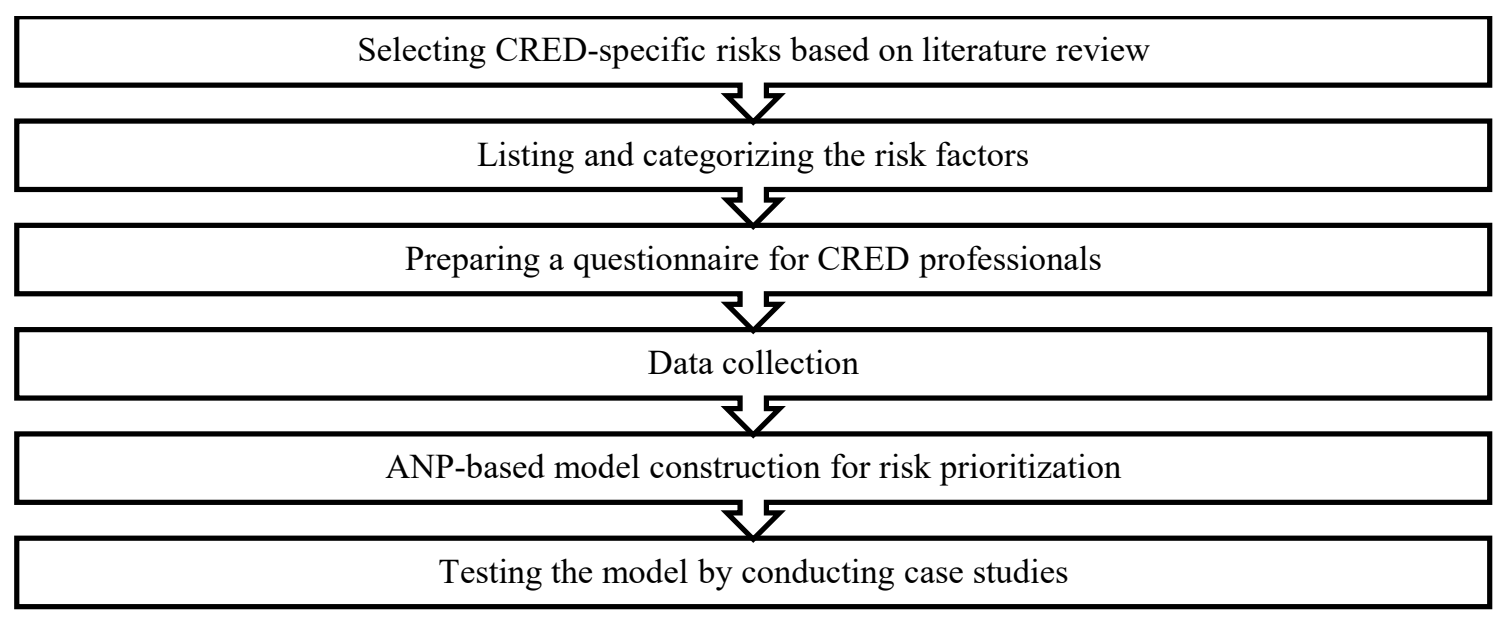

Fig. 1. Main framework of study 


\subsection{Risk identification for the model}

We initially conducted a comprehensive literature search using predetermined keywords in 10 journals. In the review process, the following keywords are searched for; "risk factors/criteria," "risk assessment," "risk management," "risk allocation," and "decision making." We excluded the manuscripts published before 1999, and we tried to include studies that are specifically about real estate development projects. Due to the limited number of studies analyzing risk factors specific to real estate development projects, we also considered studies examining general construction risks. As a result, we included papers published only in peer-reviewed journals. Finally, we selected 19 studies [7,11,15,17-20,24-35]to identify risk factors. Subsequently, we developed an initial risk factor list consisting of 108 risks under 34 categories. Since the contents and references of the studies are similar, we have combined some risk factors with comparable definitions. Relevant groups were also incorporated to identify the main risk factor categories of the model. For instance, political risks, regulatory/policy risks, and country risk groups are gathered as Political Risks.

Similarly, financial risks, investment risks, market-related risks, and economic risks are merged into Monetary Risks. A focus group consists of two industry experts and an academician who reviewed the risk factor list. After making the necessary changes, the final risk factor list is approved by the focus group. Consequently, 21 risk factors were divided into Political, Monetary, Environmental, and Project Risks. Table 1 shows the final 21 risk factors, their main risk groups, and the associated references.

As one can see from Table 1, the risk clusters of the model consist of related sub-categories. Similar groups are combined and gathered under the same related major group. The contents of the major risk groups were determined as follows:

(1) Political Risks: Considering unstable political situations and legislation issues in developing countries, political risks are of vital importance. In previous construction risk assessment researches, political-related risks were evaluated under various categories. Huffman [18] grouped them as Regulatory Risks; Gehner et al. [4] entitled Legal Risks; Dikmen et al. [28] reviewed Country Risks. In the current study, we preferred to determine those risks under the same category. Therefore, under Political Risks, we examined Political Risks, Regulatory/Policy Risks, Country, and Legal Risks.

(2) Monetary Risks: Economics and finance-related risks have a crucial role in the decision-making process of CRED projects. Especially when we consider economic instability in developing countries, it is inevitable to evaluate these types of risks. Economics and finance-related risks are frequently evaluated under various categories by researchers. Andrić et al. [35] included Economic Risks in the Construction Market category, while Shen et al. [24] created the Financial Risks group for them. Besides, Liu et al. [17] gathered possible economic risks under the Macroeconomic Risk category. Hence, to merge similar risks under these different categories, we used the Monetary Risks cluster, including Financial Risks, Investment Risks, Market Related Risks, and Economic Risks.

(3) Environmental Risks: Since the construction projects are operated on the fields easily exposed to natural events, acts of God, overwhelming and unpreventable circumstances caused exclusively by forces of nature should be seriously considered. Most of the researchers evaluated such risks under the Environmental Risks category (e.g., $[19,20,34])$. Similarly, this study evaluates the Environmental Risks, Acts of Gods, Physical Risks, and Natural Risks under the Environmental Risk group.

(4) Project Risks: Most construction-specific risk assessment studies in the literature have evaluated project risks from various perspectives as construction projects are inherently risky (e.g., 27,31,36-38). Specifically, CRED projects include a wide range of project-related risks, including changes in scope, engineering and design risks, site condition risks, managerial risks, and location risks (e.g., $[4,19,20,22])$. 
Table 1. Risk factors in CRED projects.

\begin{tabular}{|c|c|c|c|c|c|c|c|c|c|c|c|c|c|c|c|c|c|c|c|c|c|}
\hline Clusters & No & Sub Criteria & 존 & $\Xi$ & $\stackrel{n}{=}$ & 7 & $\infty$ & a & ్ㅗ & $\underset{\mathbb{I}}{\bar{I}}$ & $\sqrt{\mathfrak{d}}$ & $\overline{\mathbb{Z}}$ & 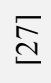 & $\stackrel{\infty}{\stackrel{్}{ు}}$ & 기 & ల్ల & $\overline{\bar{m}}$ & $\overline{\widetilde{2}}$ & $\stackrel{\bar{n}}{\infty}$ & 跑 & $\bar{n}$ \\
\hline \multirow{4}{*}{$\begin{array}{l}\text { Political } \\
\text { Risks }\end{array}$} & 1 & Political instability & $\checkmark$ & $\checkmark$ & $\checkmark$ & $\checkmark$ & & & & $\checkmark$ & $\checkmark$ & $\checkmark$ & & & $\checkmark$ & $\checkmark$ & $\checkmark$ & $\checkmark$ & $\checkmark$ & $\checkmark$ & $\checkmark$ \\
\hline & 2 & $\begin{array}{l}\text { Inconsistency in } \\
\text { policies, laws, and } \\
\text { regulation }\end{array}$ & $\checkmark$ & $\checkmark$ & $\checkmark$ & $\checkmark$ & $\checkmark$ & & & $\checkmark$ & $\checkmark$ & $\checkmark$ & & & $\checkmark$ & & & $\checkmark$ & $\checkmark$ & $\checkmark$ & $\checkmark$ \\
\hline & 3 & $\begin{array}{l}\text { Civil disorder, terrorist } \\
\text { attack, group protests }\end{array}$ & $\checkmark$ & & & $\checkmark$ & & & $\checkmark$ & $\checkmark$ & & & & & & & $\checkmark$ & $\checkmark$ & $\checkmark$ & & \\
\hline & 4 & Bureaucratic problems & $\checkmark$ & $\checkmark$ & $\checkmark$ & $\checkmark$ & $\checkmark$ & & $\checkmark$ & $\checkmark$ & $\checkmark$ & $\checkmark$ & $\checkmark$ & $\checkmark$ & $\checkmark$ & $\checkmark$ & $\checkmark$ & $\checkmark$ & $\checkmark$ & $\checkmark$ & \\
\hline \multirow{8}{*}{$\begin{array}{l}\text { Monetary } \\
\text { Risks }\end{array}$} & 5 & $\begin{array}{l}\text { Inflation and interest } \\
\text { rate fluctuation }\end{array}$ & $\checkmark$ & $\checkmark$ & $\checkmark$ & $\checkmark$ & $\checkmark$ & $\checkmark$ & $\checkmark$ & $\checkmark$ & $\checkmark$ & $\checkmark$ & & & $\checkmark$ & $\checkmark$ & $\checkmark$ & $\checkmark$ & $\checkmark$ & & $\checkmark$ \\
\hline & 6 & $\begin{array}{l}\text { Exchange rate } \\
\text { fluctuation }\end{array}$ & $\checkmark$ & & & $\checkmark$ & & $\checkmark$ & $\checkmark$ & & $\checkmark$ & & & & & $\checkmark$ & $\checkmark$ & $\checkmark$ & $\checkmark$ & & $\checkmark$ \\
\hline & 7 & Selling or leasing rate & $\checkmark$ & & & & $\checkmark$ & $\checkmark$ & $\checkmark$ & & & & & & & & & & & & \\
\hline & 8 & Investment return & $\checkmark$ & $\checkmark$ & $\checkmark$ & & $\checkmark$ & $\checkmark$ & $\checkmark$ & $\checkmark$ & $\checkmark$ & & & & $\checkmark$ & $\checkmark$ & $\checkmark$ & $\checkmark$ & $\checkmark$ & $\checkmark$ & $\checkmark$ \\
\hline & 9 & $\begin{array}{l}\text { Market liquidity or exit } \\
\text { options }\end{array}$ & $\checkmark$ & $\checkmark$ & $\checkmark$ & $\checkmark$ & $\checkmark$ & $\checkmark$ & $\checkmark$ & $\checkmark$ & $\checkmark$ & $\checkmark$ & & & & $\checkmark$ & & $\checkmark$ & $\checkmark$ & & \\
\hline & 10 & Competitiveness & $\checkmark$ & & & & $\checkmark$ & $\checkmark$ & $\checkmark$ & $\checkmark$ & $\checkmark$ & & & & & & & $\checkmark$ & $\checkmark$ & & \\
\hline & 11 & $\begin{array}{l}\text { Capital Expenditure } \\
\text { (Capex) per sqm }\end{array}$ & $\checkmark$ & & & & & $\checkmark$ & $\checkmark$ & & & & & & & & & & & & \\
\hline & 12 & $\begin{array}{l}\text { Developer or local } \\
\text { partner (if any) } \\
\text { reputation }\end{array}$ & $\checkmark$ & $\checkmark$ & $\checkmark$ & $\checkmark$ & & $\checkmark$ & & $\checkmark$ & $\checkmark$ & $\checkmark$ & $\checkmark$ & $\checkmark$ & & $\checkmark$ & $\checkmark$ & $\checkmark$ & & $\checkmark$ & \\
\hline \multirow{2}{*}{ Env. Risks } & 13 & Force Majeure & $\checkmark$ & & $\checkmark$ & $\checkmark$ & $\checkmark$ & $\checkmark$ & $\checkmark$ & $\checkmark$ & $\checkmark$ & $\checkmark$ & & & $\checkmark$ & $\checkmark$ & & $\checkmark$ & $\checkmark$ & $\checkmark$ & $\checkmark$ \\
\hline & 14 & Climatic change & $\checkmark$ & & $\checkmark$ & & $\checkmark$ & $\checkmark$ & $\checkmark$ & $\checkmark$ & $\checkmark$ & $\checkmark$ & & & $\checkmark$ & $\checkmark$ & & $\checkmark$ & & $\checkmark$ & $\checkmark$ \\
\hline \multirow{7}{*}{$\begin{array}{l}\text { Project } \\
\text { Risks }\end{array}$} & 15 & Site conditions & $\checkmark$ & & & $\checkmark$ & $\checkmark$ & $\checkmark$ & $\checkmark$ & $\checkmark$ & & & & & & $\checkmark$ & $\checkmark$ & & $\checkmark$ & $\checkmark$ & $\checkmark$ \\
\hline & 16 & $\begin{array}{l}\text { Designers and } \\
\text { constructors' } \\
\text { performance }\end{array}$ & $\checkmark$ & $\checkmark$ & $\checkmark$ & $\checkmark$ & & $\checkmark$ & $\checkmark$ & $\checkmark$ & $\checkmark$ & $\checkmark$ & $\checkmark$ & $\checkmark$ & & $\checkmark$ & $\checkmark$ & $\checkmark$ & $\checkmark$ & $\checkmark$ & $\checkmark$ \\
\hline & 17 & Technical difficulties & $\checkmark$ & $\checkmark$ & $\checkmark$ & $\checkmark$ & $\checkmark$ & $\checkmark$ & $\checkmark$ & $\checkmark$ & $\checkmark$ & & $\checkmark$ & $\checkmark$ & $\checkmark$ & $\checkmark$ & $\checkmark$ & $\checkmark$ & $\checkmark$ & $\checkmark$ & $\checkmark$ \\
\hline & 18 & Location Selection & & & & & & & & $\checkmark$ & $\checkmark$ & $\checkmark$ & & & & & & & & & \\
\hline & 19 & Infrastructure usability & $\checkmark$ & & & $\checkmark$ & & $\checkmark$ & $\checkmark$ & $\checkmark$ & $\checkmark$ & $\checkmark$ & & & & & & $\checkmark$ & & $\checkmark$ & $\checkmark$ \\
\hline & 20 & $\begin{array}{l}\text { Design and } \\
\text { Construction Changes }\end{array}$ & $\checkmark$ & $\checkmark$ & & $\checkmark$ & $\checkmark$ & $\checkmark$ & $\checkmark$ & $\checkmark$ & $\checkmark$ & $\checkmark$ & $\checkmark$ & $\checkmark$ & $\checkmark$ & $\checkmark$ & $\checkmark$ & $\checkmark$ & $\checkmark$ & $\checkmark$ & $\checkmark$ \\
\hline & 21 & Facilities management & $\checkmark$ & & & & $\checkmark$ & $\checkmark$ & $\checkmark$ & $\checkmark$ & $\checkmark$ & $\checkmark$ & & & & & & $\checkmark$ & & & \\
\hline
\end{tabular}

Briefly, this category includes the risks related to any project phase, from design to management. The previous studies evaluated these types of risks using various category titles. For example, Chen and Khumpaisal [19] examined project-specific risks as Technological Risks; Dikmen and Birgonul [27] labeled them as Project Risks, and Zhang and Zou [31] preferred to list them under the Project Specific Risk category. This study merged and evaluated Technical, Technological, Construction Related and Social Risks, such as workforce market and labor, under the Project Risks category. 


\subsection{Risk prioritization for the model}

After defining and classifying the risk factors in CRED projects, the next step is to determine the importance of their effects on the decision-making process. Since each risk factor has a different impact on the project, a multi-criteria decisionmaking selection can be employed to evaluate their degree of importance. The Analytical Hierarchy Process (AHP), which creates a hierarchical structure, has been one of the most preferred construction industry decision-making methodologies [39]. In addition to being easy to apply, it also helps decision-makers assess their judgment's consistency through its analytic feature [40]. However, many decision problems cannot be hierarchically structured because they involve the interaction and dependence of higher-level elements in a hierarchy of lower-level elements [41]. In such cases, instead of AHP, the Analytical Network Process (ANP) can be utilized to overcome the limitations of AHP. While the AHP represents a framework with a uni-directional hierarchical relationship, the ANP allows for complex interrelationships among decision levels and attributes [42]. The ANP is a general form of AHP and allows interdependencies, outer dependencies among decision elements in the hierarchical or non-hierarchical structures.

To sum up, allowing interrelations between levels, ANP presents a comprehensive analysis that involves a great variety of elements (e.g., [43]). As construction projects involve complex interrelationships among decision levels, they cannot be structured hierarchically. The interaction and dependence of higher-level elements in a hierarchy on lower-level elements require an alternative approach [41]. Accordingly, ANP gains more attraction since it provides flexibility to model real-life cases. The ANP method was implemented for several construction industry cases, such as contractor qualification, competitiveness of global construction companies, green building evaluation, and project location decision (e.g., [44-47]).

Since the real estate projects have multivariate risk factors that affect each other, considering the relation between the factors gives more accurate results. According to Tang and Li [48], ANP is an efficient and feasible method for the decisionmaking process in real estate investments. Chen and Khumpaisal [19] developed an ANP model, a novel decision-making approach for risk assessment in commercial real estate development against social, economic, environmental, and technological (SEET) criteria. The model is also tested through a case study that aims to select the best real estate investment alternative in Liverpool City Center. Accordingly, Chen and Khumpaisal [19] concluded that ANP could be an effective tool to support developers in the decision-making process based on risk assessment. Similarly, Thilini and Wickramaarachchi [20] also utilized the ANP method in the decision-making process to examine the risks faced in CRED projects and find the less risky project alternative in Gampaha, Sri Lanka. The interrelations between the elements are taken into account to reflect the nature of the real CRED cases in this study. For this purpose, we also utilized ANP to obtain more exact and realistic consequences from the network model to be evaluated.

\subsection{ANP Implementation}

Saaty [49] proposed the ANP approach, which enables interdependencies between the network's criteria. Many researchers have utilized this method frequently because decision-making problems mainly include interdependency. In this study, we applied the following four steps to developing our model considering Saaty's ANP framework.

\section{Model construction}

At first, the process starts with the definition of the problem. The decision problem needs to be broken down into a network model consisting of various components [50]. Therefore, related criteria, subcriteria, and alternatives are structured under the problem hierarchically. Once the criteria and subcriteria are formed, the network model is completed by allowing the interactions between criteria and sub-criteria as inner and outer dependencies. At this point, the elements should be compared, and the interrelations should be determined correctly. The 
critical point is that only direct relation should be considered; indirect connections should be neglected. Eventually, the network structure is established.

\section{Pairwise comparison}

Secondly, pairwise comparisons are utilized to compute the priorities and relative importance weights of the elements. Pairwise comparison matrices were evaluated row by row, and each risk factor or node was compared against others. While filling the matrices, the importance of the elements should be compared regarding the related criterion's influence. For this comparison, Saaty [40] proposed a nine-point Likert scale. According to this scale, a point of 1 indicates equal importance of the elements. In contrast, 9 shows extreme importance, which means that the row element is extremely important than the compared column element. After the whole comparison matrices are filled, a priority vector is obtained. By normalizing this vector, the priority value can be calculated for each criterion. In this respect, the consistency ratio should be taken into account for pairwise matrices. According to Saaty [51], there are three acceptable levels for consistency: 0.05 for a 3-by-3 matrix, 0.08 for a $4-$ by- 4 matrix, and 0.10 for other matrices. Therefore, the consistency ratio is supposed to be less than the recommended level of 0.10 .

\section{Super-matrix formation}

In the third step, a super-matrix is constructed to include the entire interdependencies among the elements in the calculation. This super-matrix, which is a synthesized matrix, is obtained from the combination of pairwise comparisons. To obtain the super-matrix, three matrices should be calculated: unweighted matrix, weighted matrix, and limit matrix. Firstly, the unweighted supermatrix is formed by the priorities obtained from the pairwise comparisons. Secondly, by multiplying the unweighted super-matrix values with their related cluster's weights, the weighted matrix is calculated. Then, the super-matrix is normalized, and the sum of the super-matrix columns becomes equal to 1 , namely, stochastic. To make calculations on the unweighted super-matrix, it is needed to make the matrix stochastic. Lastly, the limit matrix is computed by modifying the weighted supermatrix to powers until the weights corresponding to any node are equal [52].

\section{Choosing the best alternative}

The importance weights of the alternatives are obtained from the limit super-matrix. The alternative, which has the highest importance weight, is the best option. In our case, the criterion having the highest importance weight is the most crucial factor that affects the decision process. In this study, the ANP model was developed by following these four steps, and Super Decisions software was utilized to evaluate the priorities and the importance of weights.

\section{Data collection}

After the risk factor list is constructed, we gathered data from the industry experts to perform interrelations between factors and order the relation matrix to obtain pairwise comparisons. For this step, an expert team is formed. According to Dikmen et al. [53], there is no minimum number for panel size in this model. However, it is common to conduct ANP exercises with the participation of three or more experts. Therefore, five project team members came together for this study. The expert team is selected among engineers, architectures experienced in the CRED project. All the participants work in an international real estate development company with a wide variety of property, retail, and hospitality projects. Besides the US and Europe, the company operates many projects in developing countries in various regions such as the Middle East and North Africa. During the interview, the team members were working on CRED projects in a developing country. Considering the expertise areas and the number of years of experience in the CRED projects, the expert team members may be the representative of the sector. In other words, they are eligible to conduct the risk assessment of CRED projects in developing countries. Table 2 shows the expert team members' positions and experience details. 
Table 2. Expert team information

\begin{tabular}{llll}
\hline No & Position Detail & Experience (Years) & Expertise \\
\hline 1 & Business Development & 15 & Retail, Office, and Hotel \\
2 & Director Operations & 10 & Retail, Office, and Hotel \\
3 & Director Architectural & 16 & Retail, Office, and Hotel \\
4 & Director Asset Manager & 8 & Retail, Office \\
5 & Leasing Manager & 6 & Retail, Office \\
\hline
\end{tabular}

The data was collected through a paper-based questionnaire. After the ANP procedure is explained, the expert team members identified the dependencies between the factors and filled the interrelations matrix manually by reviewing risk criteria. Subsequently, relative importance is determined, and the expert team scored the prepared pairwise comparison matrices using the Likert scale. Because some incompatibilities are observed in the collected data, two meetings were organized to evaluate interrelations and pairwise matrices. Based on their professional backgrounds, the experts assessed and discussed the filled matrices together, and a consensus was provided by making minor arrangements.

\section{Model formation}

After obtaining the interdependencies, the next step is to form a pairwise comparison among the clusters and nodes. For this step, we developed a model in Super Decisions software by entering the interdependency inputs and connecting interrelated variables. Then, we obtained the matrices as a software output. In the second session of the expert meeting, all pairwise matrices are given to the experts and requested to evaluate them using a ninepoint Likert scale. Fig. 2 shows the ANP model structure.

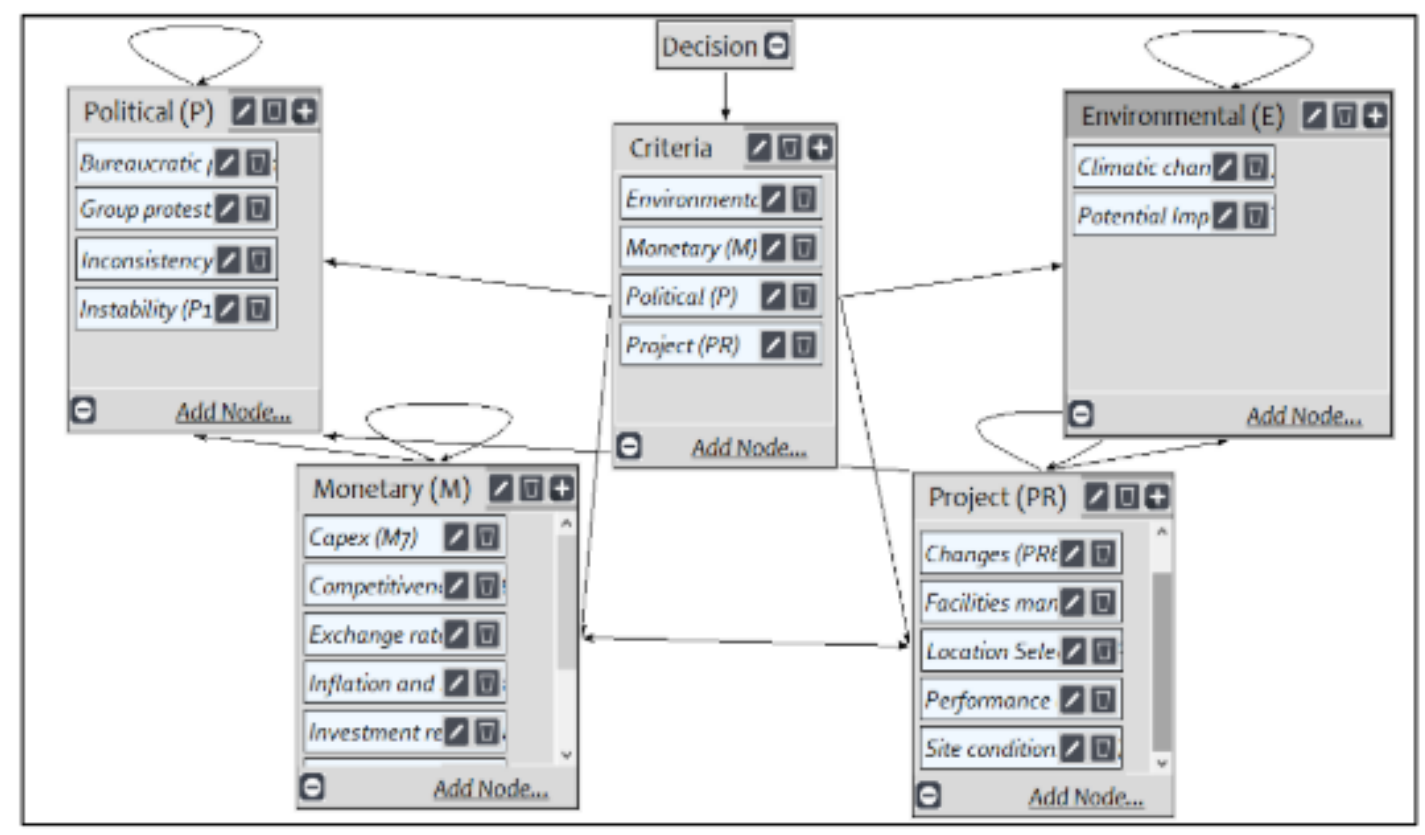

Fig. 2. ANP Model Construction 


\subsection{Pairwise comparison matrices}

As mentioned earlier, ANP focuses on interdependencies between elements and makes comparisons between clusters by examining how many times an element is more important than another element. Some representative matrices filled by the team are provided in Table 3-6 to explain the theory.

After the matrices are filled, we formed the network structure using the Super Decisions software program. All nodes, clusters, hierarchical systems, and interrelations are defined clearly in the program, and the data given by the expert team are entered into the software.

Table 3. Pairwise comparison with respect to the market liquidity.

\begin{tabular}{lccc}
\hline Market Liquidity & P3 & P2 & P1 \\
\hline P3 & 1 & $1 / 3$ & $1 / 4$ \\
P2 & 3 & 1 & $1 / 2$ \\
P1 & 4 & 2 & 1 \\
\hline
\end{tabular}

Table 4. Pairwise Comparison with respect to the Site Condition Site.

\begin{tabular}{lcc}
\hline Site Conditions & E2 & E1 \\
\hline E2 & 1 & $1 / 2$ \\
E1 & 2 & 1 \\
\hline
\end{tabular}

Table 5. Pairwise comparison with respect to the site condition site

\begin{tabular}{lcc}
\hline Bureaucratic Problems & P3 & P2 \\
\hline P3 & 1 & $1 / 4$ \\
P2 & 4 & 1 \\
\hline
\end{tabular}

Table 6. Political cluster pairwise comparison matrix.

\begin{tabular}{lcccc}
\hline Political & P4 & P3 & P2 & P1 \\
\hline P4 & 1 & 4 & $1 / 2$ & $1 / 3$ \\
P3 & $1 / 4$ & 1 & $1 / 2$ & $1 / 4$ \\
P2 & 2 & 2 & 1 & $1 / 2$ \\
P1 & 3 & 4 & 2 & 1 \\
\hline
\end{tabular}

\section{Findings}

All priorities of clusters and nodes are listed in Table 7. According to the results, Monetary Risks (M) cluster has the highest priority (0.55), and the Political Risks (P) group follows it as the second one (0.24).

Multiplying the node priorities by related cluster priorities, we calculated the importance weights of each risk factor. The results are also presented in Table 7. Accordingly, the most important risk factor is the Exchange rate fluctuation, which belongs to the Monetary Risks cluster.

\section{Testing the model}

A new expert team was formed to test the proposed model. We asked them to consider one of the CRED projects they were involved in and share the projects' details. All expert profiles and case study project details are given below in Table 8. Expert team members evaluated CRED projects on a continuous scale ranging between $0-100$ for each risk factor. In Table 9, all scores related to the degree of risks affecting the projects are shown. The aim is to determine the effects of potential risks in the decision-making process in CRED projects.

We multiplied the importance weights obtained from the ANP model by corresponding experts scoring values to get the calculated scores. On the other hand, each team member determined the overall score in terms of feasibility stages for selected CRED projects. Then, we averaged the overall scores given by the experts to calculate the Actual Score. Table 10 presents all calculated and actual scoring data, together with error rates. These case studies have error rates between $7.5 \%-15.1$ $\%$. The three cases (Case 1, Case 2, and Case 3) have less than a $10 \%$ error rate. However, it should be noted that all scoring values are subjective, and it might change from developer to developer and according to their risk perception.

\section{Discussion}

By creating significant trading areas, the CRED industry contributes to the national economy. 
Table 7. Cluster/ nodes priorities and importance weights

\begin{tabular}{|c|c|c|c|}
\hline Code & Clusters-Nodes & Priorities & Importance Weight \\
\hline $\mathrm{P}$ & Political Risks & 0.24314 & \\
\hline P1 & Instability & 0.73703 & 0.179201 \\
\hline P2 & Inconsistency & 0.14204 & 0.034536 \\
\hline P3 & Group protests & 0.06244 & 0.015182 \\
\hline P4 & Bureaucratic problems & 0.05848 & 0.014219 \\
\hline M & Monetary Risks & 0.55133 & \\
\hline M1 & Inflation and interest rate & 0.21613 & 0.119159 \\
\hline M2 & Exchange rate & 0.37348 & 0.205911 \\
\hline M3 & Selling leasing rate & 0.05738 & 0.031635 \\
\hline M4 & Investment return & 0.07992 & 0.044062 \\
\hline M5 & Market liquidity & 0.14459 & 0.079717 \\
\hline M6 & Competitiveness & 0.09681 & 0.053374 \\
\hline M7 & Capex & 0.01784 & 0.009836 \\
\hline M8 & Reputation & 0.01385 & 0.007636 \\
\hline $\mathrm{E}$ & Environmental & 0.0533 & \\
\hline E1 & Force Majeure & 0.42361 & 0.022578 \\
\hline E2 & Climatic change & 0.57639 & 0.030722 \\
\hline PR & Project & 0.15224 & \\
\hline PR1 & Site conditions & 0.1002 & 0.015254 \\
\hline PR2 & Performance & 0.18763 & 0.028565 \\
\hline PR3 & Technical & 0.09353 & 0.014239 \\
\hline PR4 & Location Selection & 0.37635 & 0.057296 \\
\hline PR5 & Accessibility & 0.12622 & 0.019216 \\
\hline PR6 & Changes & 0.029 & 0.004415 \\
\hline PR7 & Facilities management & 0.08707 & 0.013256 \\
\hline
\end{tabular}

Table 8 Case studies details

\begin{tabular}{llcc}
\hline No. & Project Type & Size & Location \\
\hline Case 1 & Retail, Theme Park Center, Marine & 255 million USD & Istanbul \\
Case 1 & Retail & 870 million TL & Istanbul \\
Case 3 & Mixed Used Development & 2,5 Billion USD & Istanbul \\
Case 4 & Mixed Used Development & 1,2 Billion USD & Antalya \\
Case 5 & Office Building & 125 million USD & Istanbul \\
\hline
\end{tabular}


Table 9. Case study scoring and testing the model

\begin{tabular}{|c|c|c|c|c|c|}
\hline No. & Case 1 & Case 1 & Case 3 & Case 4 & Case 5 \\
\hline P1 & 90 & 80 & 85 & 90 & 85 \\
\hline P2 & 60 & 60 & 90 & 85 & 80 \\
\hline P3 & 50 & 75 & 70 & 75 & 60 \\
\hline P4 & 85 & 70 & 85 & 80 & 75 \\
\hline M1 & 95 & 95 & 95 & 90 & 95 \\
\hline M2 & 95 & 95 & 95 & 90 & 95 \\
\hline M3 & 95 & 90 & 85 & 90 & 90 \\
\hline M4 & 95 & 90 & 85 & 90 & 90 \\
\hline M5 & 80 & 80 & 85 & 85 & 85 \\
\hline M6 & 80 & 85 & 85 & 80 & 75 \\
\hline M7 & 85 & 80 & 70 & 60 & 70 \\
\hline M8 & 85 & 90 & 65 & 60 & 70 \\
\hline E1 & 70 & 60 & 70 & 70 & 60 \\
\hline E2 & 60 & 60 & 40 & 30 & 50 \\
\hline PR1 & 85 & 80 & 90 & 60 & 80 \\
\hline PR2 & 80 & 85 & 70 & 70 & 80 \\
\hline PR3 & 85 & 75 & 60 & 70 & 75 \\
\hline PR4 & 95 & 95 & 90 & 90 & 90 \\
\hline PR5 & 85 & 80 & 70 & 80 & 80 \\
\hline PR6 & 75 & 80 & 85 & 80 & 80 \\
\hline PR7 & 80 & 85 & 70 & 60 & 65 \\
\hline
\end{tabular}

Each year, developed countries invest a substantial amount of capital in CRED projects. According to statistics, in 2019, Germany invested 73.44 billion euros in this industry. Furthermore, in developing countries, the fast-growing middle class creates a great demand for these commercial areas. Therefore, the interactive relationship between GDP and CRED has an essential role in developing countries. Accordingly, in the CRED industry, determining the relevant risk factors and their effects on the decision-making process is of great importance. Therefore, this study aims to provide a decision-making approach to assess CRED projects' risk criteria by developing a model based on the ANP theory.

According to the results presented in Table 7, Monetary and Political risk factors are of great importance on development projects. The Monetary Risk category has a weight of about $50 \%$ in the CRED development decision. Exchange rate fluctuation and Inflation, and interest rate fluctuation factors stand out among this category's items. Crosby et al. [54] state that economic factors such as interest rate impact the commercial real estate industry's demand and supply. Additionally, as Chen and Khumpaisal [19] mentioned, financial and economic issues are quite significant in the real estate industry, and they can enormously affect the entire project. As an example, the subprime mortgage crisis directly affected the real estate sector in the world and the economy of many countries. Nevertheless, developing countries were affected much more during the crisis period than developed countries [55]. The demand and 
investment from developed countries significantly declined. Thus, developing countries faced more downsizing with structural problems in their emerging economies. As financial stability is a more significant concern for developing countries, it is not surprising that the monetary risk category has a higher weight among all the groups.

On the other hand, in the Political risk factors category, Political Instability and Inconsistency in Policies sub-factors weigh more than $20 \%$. In their study, Chen and Khumpaisal [19] did not evaluate the ANP model's political risks selecting the most suitable CRED plan in Liverpool. However, as we mentioned before, developing countries have different dynamics than developed countries, such as an unstable political environment. More importantly, these risks are called uncontrollable risks, so more challenging for decision-makers to manage such risks. Therefore, these risks, which are more critical in developing countries, need to be assessed consistently [56]. Thilini and Wickramaarachchi [20] evaluated Political Groups, Commercial Tax Policy, and Council Approval sub-criteria under the Political Risks group. They stated that political risks are crucial for CRED projects in Sri Lanka, a developing country, due to unstable political situations. Moreover, the findings show that Council Approval has the highest priority among 32 factors. However, this ranking result might be misleading because the study presents the weights of the risk factors normalized by each cluster. In other words, it evaluates a risk factor only among the members of the same risk cluster. Accordingly, the sum of the weights of risk factors listed under the same cluster is equal to one. However, the normalized weights should not be used to make a direct comparison. Shortly, the study results may be inaccurate for a direct comparison of risk factors in a separate cluster. Consequently, Thilini and Wickramaarachchi [20] found that the Council Approval factor is the most critical criterion in the Political Risks cluster. After all, it is indicated that besides Monetary Risks, Political Risks are also crucial in affecting the development decision in developing countries. Accordingly, the developers, stakeholders, or other decision-makers should prepare their contingency plan to mitigate the consequence of adverse risks and promptly respond to these risk groups.

Results showed that the Project Risk cluster ranked as the third most crucial risk group, with the importance weight of 0.152 . In particular, we concluded that the Location Selection risk factor from the Project Risk cluster is the most significant for CRED projects by ranking fifth among all other risk factors. Considering the nature and aim of CRE properties, the project location is crucial for developers. The selection of a wrong place causes the loss of investment for commercial properties [47]. The project's demand can be affected by numerous factors such as accessibility, land cost, and potential future developments around the area. Additionally, the location of a CRED project such as a shopping mall directly affects the target customer group since the demographic features of the region define the demand for various services. Accordingly, project-related risks are assessed in most real estate-related studies (e.g., [4,18-20]). The results show that project risks are critical for real estate projects regardless of the country or region.

Moreover, the results show that the Environmental category has the lowest weight among other risk factor categories. Under this category, the weight of the Climatic Change factor is 0.0307 , and it ranks tenth. The Force Majeure factor from the same cluster weighted 0.0225 and ranked 12 in the list. We should emphasize that the data used in the study collected in the mid of 2019. Therefore, if we consider the current pandemic situation around the world, this result could have been different. Since the coronavirus outbreak affects many sectors, including real estate development, people noticed that the act of god has a significant impact on project plans. Many construction projects are suspended now, and the industry value chain is directly affected by the situation. Not surprisingly, the economies and markets in developing countries, where health services are inadequate, are worse than developed ones. Accordingly, we can say that decision makers 
in developing countries should pay more attention to the Force Majeure risk factor.

Regarding the model's testing, the case studies result shows that the error rates range between $4.9 \%-15.1 \%$. Case 4 has the lowest actual score, 73 , while it has the highest error rate among all case studies. On the other hand, the actual score of Case 2 is 81 , and its error rate is $4.9 \%$. Thus, we may say that the proposed model is more successful in assessing high-risk projects. Considering these tolerable error rates, we can say that the model's outcome is reliable to obtain a feasible development decision in the direction of decision makers' risk acceptance capacity. Nevertheless, all scoring values are subjective, and it might change from developer to developer based on their risk perception. Therefore, it is necessary to collect data from as many and different project stakeholders as possible and evaluate the data obtained with this proposed model. Thus, the biased effects of this method based on subjective judgments by its nature can be minimized.

In terms of practical contributions, this study presents a way to understand risk factors. Decisionmakers of CRED projects can benefit from proposed risk factors and priorities in the decisionmaking process of project development, feasibility, or conceptual design stages. This study enables them to understand the origin of risk factors and take preventive precautions before the development phase. Although the results are valid for the CRED projects in developing countries, similar models with minor changes may be designed for other types of projects. Besides its practical and theoretical contributions, this study also has some limitations. One of the significant limitations of this study is the number of team members. The team consists of 5 engineers and architects who work at the same international real estate development company. Even though the expert team members have adequate experiences to represent the CRED industry, as an improvement, the team may be diversified. Besides engineers and architects, the finance team members, construction site team, and management team can be included in the expert team to provide different perspectives. Even though the case studies, which the newly created expert group evaluated, contribute to the study, more case studies may be conducted to validate the model. Moreover, conducting a validation study can be more reliable to present the effectiveness of the research. According to Ishizaka et al. [57], techniques validating outputs calculated by multicriteria decision methods against verifiable objective results or techniques applied to problems incorporating subjective criteria can be used to validate the model. The subjectivity of the data set is also another limitation of the study. The team evaluated the factors based on their experiences. However, the risk concept is indispensably subjective. Therefore, for a better risk assessment, the data source can be diversified, and incompatible data can be removed. Moreover, it should be noted that the CRE industry is highly dynamic and open to change. Risk factors and results may vary in different market conditions and periods. Therefore, up-to-date research and other scenarios will always be needed.

\section{Conclusion}

The CRED sector, a substantial branch of the real estate sector, is subject to several interrelated sources of risk. This study proposes an ANP model for assessing risks to CRED projects in developing countries because risk management is of greater importance due to economic and political instability in such countries. In this regard, we defined 21 risk factors and clustered them under four categories; Political, Monetary, Environmental, and Project Related. In this study, the importance weight of each risk factor and categories are calculated. Of the five most important risk factors, three are Monetary, one of them is Political, and the last one belongs to the Project cluster. Moreover, risk factors belonging to the Environmental Cluster turn out to be less critical. We also conducted five case studies to test the proposed model. The case study results show the success of the model in assessing the CRED risks with tolerable consistency. As a result, this study contributes to the literature by specifying CRED-related risk factors and provides a tool for decision-makers to be aware of the risks 
existing in CRED projects and make provision before the development stage. Significantly, decision-makers working in developing countries can benefit from the proposed model to evaluate CRED projects' risk factors. The model is developed based on subjective data since ANP was used. However, it can guide the users, and the decision-makers can continuously improve the model by considering their organizations' changing needs. Besides, considering the limitations of the study, such as the participant number in the expert team and the number of case studies, we recommend increasing the sample space for future studies. Finally, validation techniques might be included in future studies to verify the efficiency of the decision-making model.

\section{Data availability statement}

All data that support the findings of this study are available from the corresponding author upon reasonable request.

\section{Ethics committee permission}

The authors acquired ethics committee permission for surveys implemented in this manuscript from the Science and Engineering Fields Human Subjects Ethics Committee of Boğaziçi University (Date: 08.11.2020, No. 84391427-050.01.04E.17947).

\section{Declaration of conflicting interests}

The author(s) declared no potential conflicts of interest with respect to the research, authorship, and/or publication of this article.

\section{References}

[1] Kuhn S, Milasi S, Yoon S (2018) World employment social outlook: Trends 2018, Geneva: ILO.

[2] Comu S, Kural Z, Yucel B (2020) Selecting the appropriate project delivery method for real estate projects using fuzzy AHP. Journal of Construction Engineering, 3(4): 249-63.

[3] Fuller SS (2019) Economic impacts of commercial real estate. NAIOP Research Foundation.
[4] Gehner E, Halman JIM, Jonge H de. Risk management in the Dutch real estate development sector: A survey. 6th International Postgraduate Research Conference in the Built and Human Environment, 2006, University of Salford, UK.

[5] Beracha EI, Freybote J, Lin Z (2019) The determinants of the ex-ante risk premium in commercial real estate. Journal of Real Estate Research, 41(3): 411-441.

[6] Khumpaisal S, Ross A, Abdulai R (2010) An examination of Thai practitioners' perceptions of risk assessment techniques in real estate development projects. Journal of Retail \& Leisure Property, 9(2): 151-174.

[7] Khumpaisal S, Chen, Z (2010) Risk assessment in real estate development: An application of analytic network process. Journal of Architectural/Planning Research and Studies, 7(1): 103-118.

[8] Qazi A, Dikmen I, Birgonul MT (2020) Mapping uncertainty for risk and opportunity assessment in projects. Engineering Management Journal, 32(2): 86-97.

[9] Mustafa MA, Al-Bahar JF (1991) Projects risk assessment using the analytic hierarchy process. IEEE Transactions on Engineering Management, 38(1): 46-52.

[10] Akintoye AS, Macleod MJ (1997) Risk analysis and management in construction. International Journal of Project Management, 15(1): 31-38.

[11] Hastak M, Shaked A (2002) ICRAM-1: Model for international construction risk assessment. Journal of Management in Engineering, 16(1): 59-69.

[12] Kuo YC, Lu ST (2013) Using fuzzy multiple criteria decision making approach to enhance risk assessment for metropolitan construction projects. International Journal of Project Management, 31(4): 602-614.

[13] Abd El-Karim, MSBA, Mosa El Nawawy OA, Abdel-Alim AM (2017) Identification and assessment of risk factors affecting construction projects. HBRC Journal, 13(2): 202-216.

[14] Al-Bahar, JF, Crandall, KC (1990) Systematic risk management approach for construction projects. Journal of Construction Engineering and Management, 116(3): 533-546.

[15] Bing L, Tiong RLK, Fan WW, Chew DAS (1999) Risk management in international construction joint ventures. Journal of construction engineering and management, 125(4): 277-284. https://doi.org/10.1061/(ASCE)07339364(1999)125:4(277) 
[16] Nieto-Morote A, Ruz-Vila, F (2011) A fuzzy approach to construction project risk assessment. International Journal of Project Management, 29(2), 220-231.

[17] Liu J, Zhao X, Yan P (2016) Risk paths in international construction projects: Case study from Chinese contractors. Journal of Construction Engineering and Management, 142(6): 05016002.

[18] Huffman FE (2002) Corporate real estate risk management and assessment. Journal of Corporate Real Estate, 5(1): 31-41.

[19] Chen Z, Khumpaisal S (2009) An analytic network process for risks assessment in commercial real estate development. Journal of Property Investment and Finance, 27(3): 238-258.

[20] Thilini M, Wickramaarachchi NC (2019) Risk assessment in commercial real estate development: An application of analytic network process. Journal of Property Investment and Finance, 37(5): 427444.

[21] Khumpaisal S (2011) A classification of risks in real estate development business. Journal of Architectural/Planning Research and Studies, 8(2): 1-8.

[22] Hwang BG, Shan M, Supa'at NNB (2017) Green commercial building projects in Singapore: Critical risk factors and mitigation measures. Sustainable Cities and Society, 30: 237-247.

[23] Ling FYY, Hoi L (2006) Risks faced by Singapore firms when undertaking construction projects in India. International Journal of Project Management, 24(3): 261-270.

[24] Shen LY, Wu GW, Ng CS (2001) Risk assessment for construction joint ventures in China. Journal of Construction Engineering and Management. 127(1): 76-81.

[25] Thuyet VN, Stephen O, Prasanta K D (2007) Risk Management in oil and gas construction projects in Vietnam. International Journal of Energy Sector Management, 1 (2): 175-194.

[26] Bing L, Akintoye A, Edwards PJ, Hardcastle C. (2005) The Allocation of Risk in PPP/PFI Construction Projects in the UK. International Journal of Project Management, 23(1): 25-35.

[27] Dikmen I, Birgonul MT (2006) An analytical hierarchy process-based model for risk and opportunity assessment of international construction projects. Canadian Journal of Civil Engineering, 33(1): 58-68.

[28] Dikmen I, Birgonul MT, \& Han S (2007) Using fuzzy risk assessment to rate cost overrun risk in international construction projects. International Journal of Project Management, 25(5): 494-505.

[29] Perera BAKS (2009) Risk management in road construction: The case of Sri Lanka. International Journal of Strategic Property Management, 13(2): $87-102$.

[30] El-Sayegh SM, Mansou, M H (2015) Risk assessment and allocation in highway construction projects in the UAE. Journal of Management in Engineering, 31(6): 04015004.

[31] Zhang G, Zou PX (2007) Fuzzy analytical hierarchy process risk assessment approach for joint venture construction projects in China. Journal Construction Engineering Management, 133(10): 771-779.

[32] Chan AP, Yeung JF, Yu CC, Wang SQ, Ke Y (2011) Empirical study of risk assessment and allocation of public-private partnership projects in China. Journal of Management in Engineering, 27(3): 136-148.

[33] Ke, Y, Wang S, Chan AP, Cheung E (2011) Understanding the risks in China's PPP projects: Ranking of their probability and consequence. Engineering, Construction and Architectural Management, 18(5): 481-496.

[34] El-Sayegh SM, Mansour MH (2015) Risk assessment and allocation in highway construction projects in the UAE. Journal of Management in Engineering, 31(6): 04015004.

[35] Andrić JM, Wang J, Zou PX, Zhang J, Zhong R (2019) Fuzzy logic-based method for risk assessment of belt and road infrastructure projects. Journal of Construction Engineering and Management, 145(12): 04019082.

[36] Carr V, Tah JHM (2001) A fuzzy approach to construction project risk assessment and analysis: Construction project risk management system. Advances in Engineering Software, 32(10-11): 847-857.

[37] Rafindadi ADU, Mikić M, Kovačić I, Cekić Z (2014) Global perception of sustainable construction project risks. Procedia-Social and Behavioral Sciences, 119: 456-465.

[38] Samantra C, Datta S, Mahapatra SS (2017) Fuzzy based risk assessment module for metropolitan construction project: An empirical study. Engineering Applications of Artificial Intelligence, 65: 449-464.

[39] Jokar E, Aminnejad B, Lorak A (2020) Risk prioritization and selection of contractor participating in Public-Private Partnership (PPP) 
infrastructure project using Hybrid Fuzzy AHP and Fuzzy TOPSIS (Case Study: Saveh-Salafchegan Freeway Project). Journal of Construction Engineering, Management \& Innovation, 3(1):1-6.

[40] Saaty TL. The Analytic Hierarchy Process. McGraw-Hill,New York, 1980

[41] Saaty TL, Özdemir MS. The encyclicon: A dictionary of decisions with dependence and feedback based on the analytic network process. RWS Publications, 2005.

[42] Yüksel I, Dağdeviren M (2010) Using the fuzzy analytic network process (ANP) for Balanced Scorecard (BSC): A case study for a manufacturing firm. Expert Systems with Applications, 37(2): 1270-1278.

[43] Chatterjee K, Zavadskas EK, Tamošaitienè J, Adhikary K, Kar S (2018) A hybrid MCDM technique for risk management in construction projects. Symmetry, 10(2): 46.

[44] Cheng EW, Li H (2004) Contractor selection using the analytic network process. Construction management and Economics, 22(10): 1021-1032.

[45] Ozorhon B, Kus C, Caglayan S (2020) Assessing competitiveness of international contracting firms from the managerial perspective by using Analytic Network Process. Journal of Construction Engineering, Management \& Innovation, 3(1): 5266.

[46] Ignatius J, Rahman A, Yazdani M, Šaparauskas J, Haron SH (2016) An integrated fuzzy ANP-QFD approach for green building assessment. Journal of Civil Engineering and Management, 22(4): 551563. https://doi.org/10.3846/13923730.2015.1120772

[47] Cheng EW, Li H, Yu L (2005) The analytic network process (ANP) approach to location selection: A shopping mall illustration. Construction Innovation, 5(2): 83-98.
[48] Tang D, Li L. Real estate investment decisionmaking based on analytic network process. International Conference on Business Intelligence and Financial Engineering, 24-26 July 2009, Beijing, China.

[49] Saaty TL. Decision Making with Dependence and Feedback: The Analytic Network Process. RWS Publications, 1996.

[50] Saaty TL, Vargas LG. The Analytic Network Process. Decision Making with the Analytic Network Process. Springer, 2013.

[51] Saaty TL (1994) How to make a decision: the analytic hierarchy process. Informs Journal on Applied Analytics, 24(6): 19-43.

[52] Saaty TL (2001) Fundamentals of the analytic hierarchy process. The analytic hierarchy process in natural resource and environmental decision making. 15-35, Springer, Dordrecht.

[53] Dikmen I, Birgonul MT, Ozorhon B, Sapci NE (2010) Using analytic network process to assess business failure risks of construction firms. Engineering, Construction and Architectural Management, 17(4): 369-386.

[54] Crosby N, Devaney S, Nanda A (2016) Which factors drive rental depreciation rates for office and industrial properties? Journal of Real Estate Research, 38(3): 359-392.

[55] Naudé W (2009) The financial crisis of 2008 and the developing countries. No. 2009/01. WIDER Discussion Paper.

[56] Xiaopeng D, Pheng LS (2013) Understanding the critical variables affecting the level of political risks in international construction projects. $\mathrm{KSCE}$ Journal of Civil Engineering, 17(5): 895-907.

[57] Ishizaka A, Balkenborg D, Kaplan T (2011) Does AHP help us make a choice? An experimental evaluation. Journal of the Operational Research Society, 62: 1801-1812. 